\title{
Prevalence of Oral Mucosal Changes in Eluru, Andhra Pradesh (India) - An Institutional Study
}

\author{
Sudhakar S', B Praveen Kumar ${ }^{2}$, MPV Prabhat ${ }^{3}$
}

\begin{abstract}
Objective: The objective of the study was to evaluate the prevalence of oral mucosal changes (OML) in Eluru, Andhra Pradesh and to determine possible associations of OML with respect to age, gender and habits.

Materials and Methods: The study sample consisted of 3035 patients collected from outpatients seeking dental treatment in department of Oral Medicine and radiology. The subjects were interviewed by trained interviewers and underwent a clinical examination of the oral mucosa performed according to WHO guidelines. A specially prepared color atlas of OML was used for lesion recognition and confirmation.

Statistical Analysis: The data obtained were tabulated and subjected to statistical analysis utilizing the SPSS (statistical package for the social sciences) soft ware version 10.0. Pearson chi-square test was applied to test the significance between mucosal changes with respect age, gender and habits.

Results: The overall classification among 3035 samples showed 1042 cases presented with one or more mucosal changes/lesions/ conditions, which constituted a total of about 1489 lesions. Among 1489 lesions, 929 mucosal changes were either normal variants or developmental anomalies, 206 were traumatic lesions, 254 were tobacco induced, 22 were of infectious origin and 78 were miscellaneous conditions.

Conclusion: The overall mucosal changes noted in the study was $49.06 \%$ and the most prevalent lesions were linea alba, frictional keratosis and Fordyce granules. Mucosal changes were predominantly noted in males, in buccal mucosa and in the age group of 16-30 yrs.
\end{abstract}

Keywords: Oral mucosa, Prevalence, Oral cavity, Andhra Pradesh.

${ }^{1}$ Senior lecturer

Department of Oral Medicine \& Radiology,

St. Joseph Dental College \& Hospital,

Eluru (Andhra Pradesh) - 534003

Phone : 0091-9246666765

${ }^{2}$ Senior lecturer

Department of Oral Medicine \& Radiology,

St. Joseph Dental College \& Hospital,

Eluru (Andhra Pradesh) - 534003

${ }^{3}$ Associate professor

Department of Oral Medicine \& Radiology,

St. Joseph Dental College \& Hospital,

Eluru (Andhra Pradesh) -534003

\section{Contact Autbor}

Dr. S. Sudhakar

Email: drsudhakaroralmed@yahoo.co.in

J Oral Health Comm Dent 2011;5(1)42-46

\section{INTRODUCTION}

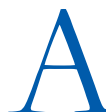
s age advances oral cavity is prone for myriad of changes. They can be developmental, physiological or pathological. Given the large number of alterations, diagnosis of the wide variety of lesions that occur in the oral cavity is an essential part of dental practice to ensure appropriate treatment. An important element in establishing a diagnosis is knowledge of the lesions relative frequency, or prevalence at one point in time ("point prevalence"). Prevalence data of oral mucosal lesions (OML) are available from many countries, however the information they provide are not always extrapolable to our population since cultural, ethnic and demographic differences exist. Despite the efforts made by different groups, establishment of prevalence data related to oral mucosa is meager in the Indian literature. Considering this, the present study was done to evaluate the prevalence of OML in Eluru, Andhra Pradesh.

\section{MATERIAL AND METHODS}

The study subjects included 3035 patients visiting as outpatients seeking dental treatment in Department of Oral Medicine and Radiology, from $10^{\text {th }}$ February 2009 to $9^{\text {th }}$ April 2009. The survey protocol was reviewed and approved by the institutional ethical committee and informed consent was obtained from a parent or guardian of each participant. The study samples were divided into six age groups: $1-15$ years (yrs); 16-30 yrs; $31-45$ yrs; $46-60$ yrs; 61-75 yrs; 75 yrs and above. Subjects with adequate mouth opening were included in the study. All the subjects were questioned for any deleterious habits such as smoking, tobacco chewing, alcohol intake, cheek chewing with their frequency and duration. The examinations of the oral cavity was performed by two independent trained examiners and confirmed by a senior 
clinician, if disparity existed. A dental chair and standard light source were used during the assessment and examination was made with a mouth mirror, explorer and gauze piece. The diagnosis was made based on the history, clinical features and chair side investigations applying WHO (World health organization) guidelines. A color atlas was utilized for clinical evaluation and in case of clinically suspicious lesion biopsies were made. The diagnosis with its anatomical location was recorded in the proforma designed for the study.

The data obtained were tabulated and subjected to statistical analysis. The following statistical methods were adopted utilizing the SPSS (stastical package for the social sciences) soft ware version 10.0. Initially the frequency distribution of each of the variable included in the study such as age, gender, awareness, habits and mucosal changes were determined and cross tabulation was prepared to show their relationship. Pearson chi-square test was applied to test the significance between mucosal changes with respect to age, gender and habits.

\section{RESULTS AND DISCUSSION}

Among 3035 samples/cases included in the study 1042 (34.33\%) subjects showed oral mucosal changes. Out of 1042 samples

\begin{tabular}{|c|c|c|c|c|c|c|}
\hline Lesions & Number & Percentage & $\begin{array}{l}\text { Point } \\
\text { prevalence } \\
\text { ranking }\end{array}$ & $\begin{array}{l}\text { ommon } \\
\text { Age group } \\
\text { Caffected }\end{array}$ & $\begin{array}{l}\text { Gender } \\
\text { Commonly } \\
\text { affected }\end{array}$ & $\begin{array}{l}\text { Site } \\
\text { Commonly } \\
\text { affected }\end{array}$ \\
\hline \multicolumn{7}{|c|}{ Normal variants and developmental anomalies } \\
\hline Linea alba & 554 & 18.25 & 1 & $16-30$ & Male & Buccal Mucosa \\
\hline Fordyce granules & 148 & 4.88 & 3 & $16-3031-45$ & Male & Buccal Mucosa \\
\hline Lingual varices & 89 & 2.93 & 5 & $61-75$ & Male & Tongue \\
\hline Leukoedema & 79 & 2.60 & 6 & $46-60$ & Male & Buccal Mucosa \\
\hline Fissured tongue & 28 & 0.92 & 10 & $46-60$ & Female & Tongue \\
\hline Physiological pigmentation & 18 & 0.59 & 13 & $16-30$ & Female & Buccal Mucosa \\
\hline Geographic tongue & 8 & 0.26 & 20 & $16-30$ & Female & Tongue \\
\hline $\begin{array}{l}\text { Ankyloglossia } \\
\text { of the mouth }\end{array}$ & 4 & 0.13 & 25 & $16-30$ & Female & Tongue \& Floor \\
\hline Median rhomboid glossitis & 1 & 0.03 & 33 & $46-60$ & Male & Tongue \\
\hline \multicolumn{7}{|l|}{ Traumatic lesions } \\
\hline Frictional keratosis & 152 & 5 & 2 & $16-3046-60$ & Male & Buccal Mucosa \\
\hline Traumatic ulcer & 30 & 0.98 & 9 & $16-30$ & Female & Buccal Mucosa \\
\hline Irritational fibroma & 17 & 0.56 & 14 & $46-60$ & Female & Buccal Mucosa \\
\hline Morsciatio & 3 & 0.09 & 27 & $16-30$ & Male & Buccal Mucosa \\
\hline Chemical burn & 2 & 0.07 & 28 & $46-60$ & Male & Buccal Mucosa \\
\hline Thermal burn & 1 & 0.03 & 33 & $46-60$ & Female & Palate \\
\hline Epulis fissuratum & 1 & 0.03 & 33 & $31-45$ & Male & Alveolar Ridge \\
\hline \multicolumn{7}{|l|}{ Tobacco-induced lesions } \\
\hline Smoker's melanosis & 106 & 3.49 & 4 & $46-60$ & Male & Buccal Mucosa \\
\hline Leukoplakia & 62 & 2.04 & 7 & $46-60$ & Male & Buccal Mucosa \\
\hline Smoker's palate & 36 & 1.18 & 8 & $46-60$ & Male & Palate \\
\hline Osmf & 21 & 0.7 & 12 & $16-30$ & Male & Buccal Mucosa \\
\hline Smoker's keraosis & 15 & 0.49 & 16 & $46-60$ & Male & Palate \\
\hline Tobacco pouch keratosis & 5 & 0.16 & 23 & $16-30$ & Male & Buccal Mucosa \\
\hline $\begin{array}{l}\text { Malignancy } \\
\text { mouth }\end{array}$ & 5 & 0.16 & 23 & $>75$ & Male & Floor of the \\
\hline Chewer's mucosa & 4 & 0.13 & 25 & $16-30$ & Male & Buccal Mucosa \\
\hline \multicolumn{7}{|l|}{ Infections } \\
\hline Angular cheilitis & 9 & 0.3 & 19 & $31-45$ & Female & Angle of mouth \\
\hline Denture stomattis & 7 & 0.23 & 21 & $46-60$ & Female & Palate \\
\hline Herpes labialis & 6 & 0.2 & 22 & $16-30$ & Female & Labial Mucosa \\
\hline \multicolumn{7}{|c|}{ Miscellaneous conditions } \\
\hline Lichenoid reaction & 24 & 0.79 & 11 & $16-30$ & Male & Buccal Mucosa \\
\hline Apthous ulcer & 17 & 0.56 & 14 & $16-30$ & Male & Buccal Mucosa \\
\hline Lichen planus & 14 & 0.46 & 18 & $46-60$ & Female & Buccal Mucosa \\
\hline Anaemic stomatitis & 15 & 0.42 & 16 & $31-45$ & Female & Buccal Mucosa \\
\hline Allergic stomatitis & 2 & 0.6 & 28 & $46-60$ & Female & Buccal Mucosa \\
\hline Hemangioma & 2 & 0.6 & 28 & $31-45$ & Male & Buccal Mucosa \\
\hline Nevus & 2 & 0.6 & 28 & $16-30$ & Female & Labial Mucosa \\
\hline Mucocele & 2 & 0.6 & 28 & $16-30$ & Female & Labial Mucosa \\
\hline
\end{tabular}




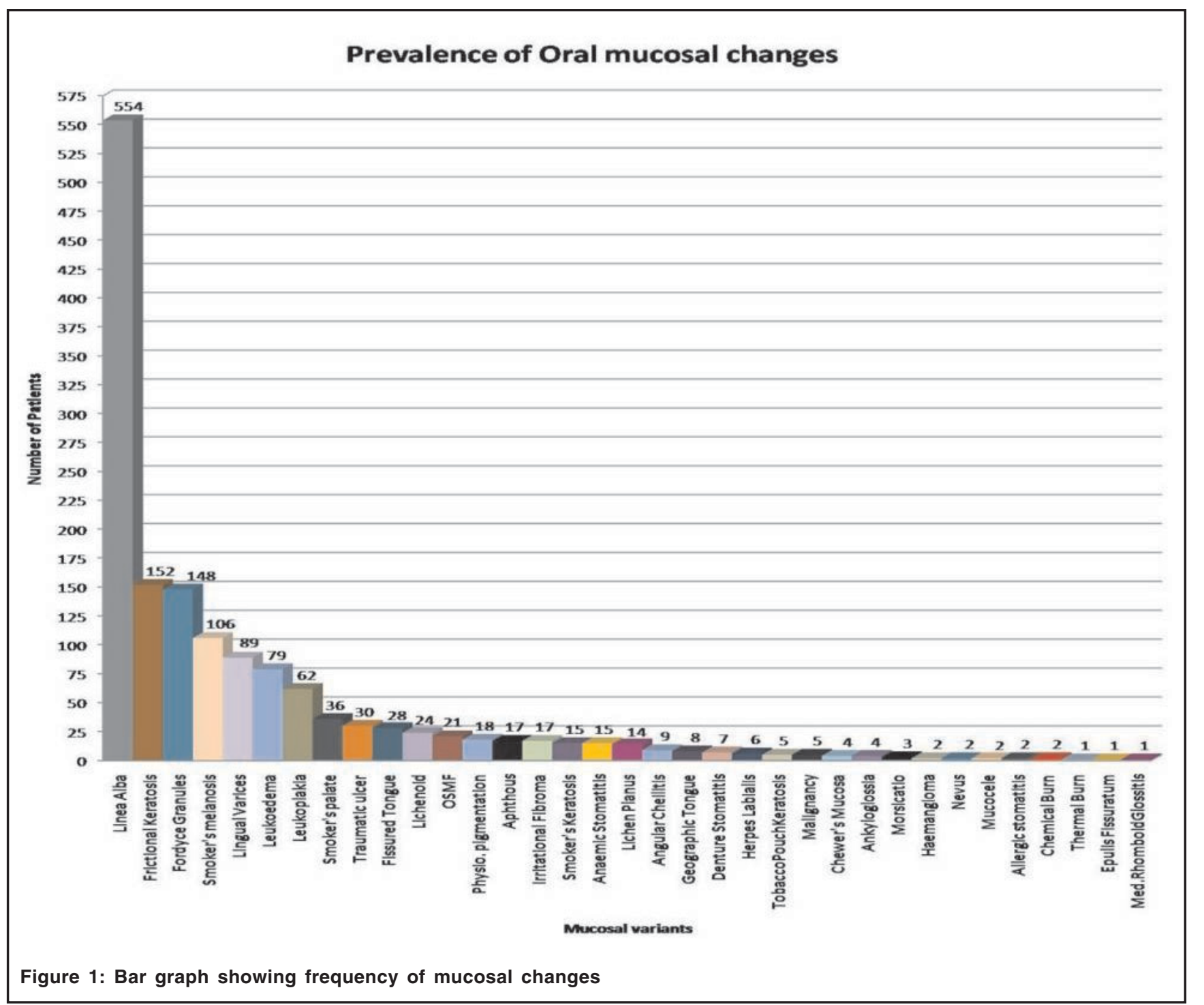

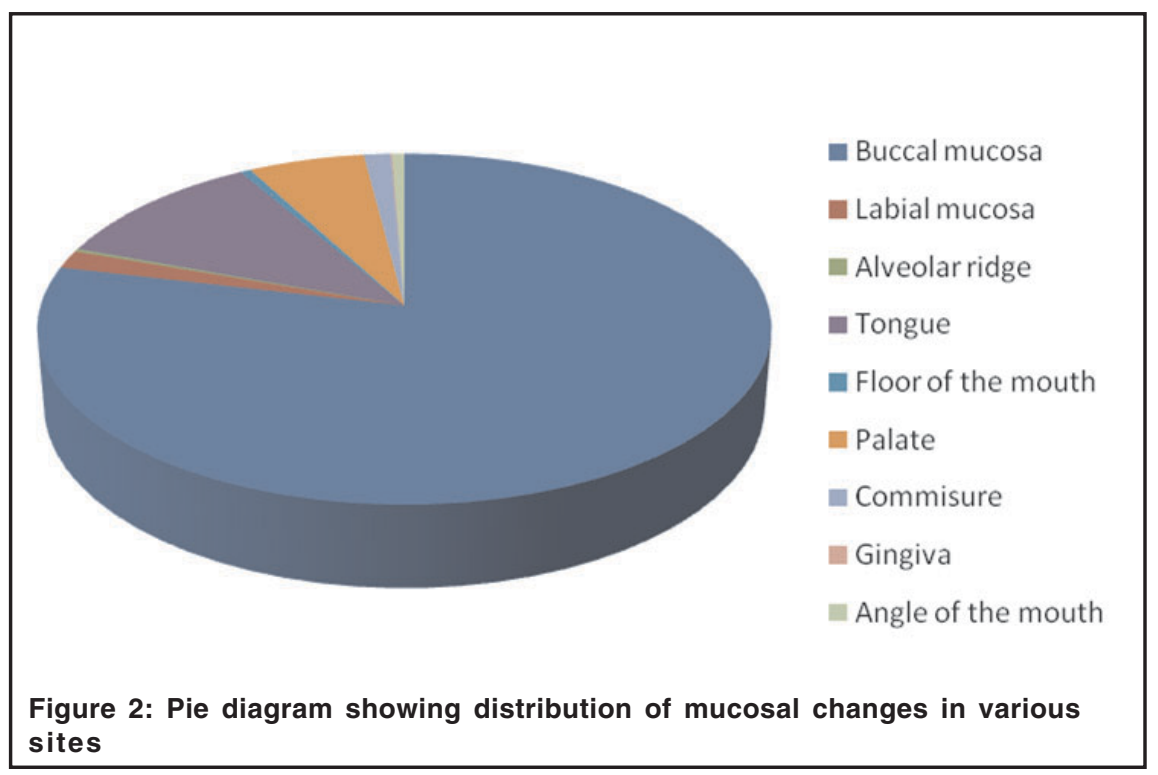

214 of them had more than one mucosal change. The affected samples (1042) when classified based on the age showed $12(1.2 \%)$ were in the age group of $1-15 \mathrm{yrs}$, $353(33.9 \%)$ were between 16-30yrs, $302(29 \%)$ were among 31-45yrs and $279(26.8 \%), 84(8.1 \%), 12(1.2 \%)$ in the age group 46-60, 61-75, 76 and above respectively (Table 1$)$.

The overall gender classification among the affected samples indicated male predominance 649(62.3\%) while females represented 393(37.7\%). Smoking habit was found very common (280 cases), followed by smokeless (55 cases) and both (45 cases); however majority of the samples (662) claimed or denied any habits, either 
in the past or at present. In respect to the awareness; only 68 cases $(6.5 \%)$ were aware of their condition, otherwise 974 cases $(93.5 \%)$ were unaware of the mucosal changes.

The overall classification among 3035 samples showed 1042 cases presented with one or more mucosal changes, which constituted a total of about 1489 (49.06\%) lesions. Among 1489 lesions, 929 mucosal changes were either normal variants or developmental anomalies, 206 were traumatic lesions, 254 were tobacco induced, 22 were of infectious origin and 78 were miscellaneous conditions (Table 1). In regard to site, majority of the lesions were seen in the buccal mucosa $(78.6 \%)$ and the least common site was gingiva $(0.27 \%$ ) (Fig 1).

\section{Normal variants and Developmental anomalies}

Among all the mucosal changes recorded in the study, linea alba was the most prevalent condition (18.25\%), which was comparatively higher than Martinez et al (10.7\%) (1). Linea alba was most commonly seen in the buccal mucosa $(99 \%)$ and $36.5 \%$ of them were seen in the age group 16-30 yrs.

Fordyce granules was seen in $4.88 \%$ of the cases, a finding which was less than Mathew et al (6.5\%) (2). An interesting finding recorded in the study was that all the 148 cases $(100 \%)$ were present in the buccal mucosa.

The prevalence of Lingual varices in the present study was $2.93 \%$. This finding was higher than Mathew et al (1.17\%) (2). However, a typical finding noted in the study was that as the age advanced the occurrence also increased and the most prevalent age group was 61-75 yrs (41\%).

Among all the normal variants found in the study, the following conditions showed consistent findings with other studies: Fissured tongue $(0.92 \%)$ with shulman et al $(0.85 \%)$ (3), Geographic tongue $(0.24 \%)$ with Bouquot (0.3\%) (4) and Ankyloglossia $0.13 \%$ with Mathew et al (0.58\%) (2).
The presence of Leukoedema was seen in $2.6 \%$ of the cases, which was less when compared with Mathew et al (3.7\%) (2). However, our study was consistent in regard to site as $97 \%$ of the cases were seen in buccal mucosa and it was seen predominately in the age group of 46-60 yrs.

Another notable variant noted in our sample was physiological pigmentation, which constituted of about $0.59 \%$, which was far below than Salonen (6.6\%) (5) and Martinez (24.6\%) (1).

\section{Traumatic lesions}

The traumatic lesions in the present study constituted about 204 cases (13.9\%). Most of the lesions were seen in the buccal mucosa and in the age group 16-30. Interestingly, the prevalence of majority of the following traumatic lesions found in the study were more consistent with the other studies: Frictional keratosis $(5 \%)$ with Mathew et al (5.79\%) (2) Traumatic ulcer $(0.98 \%)$ with Mathew et al $(1.0 \%)$ (2), Morsciatio $(0.09 \%)$ with Bouqout et al $(0.12 \%)$ (6).

The other traumatic lesions showed findings comparable with various studies include: Chemical burn (0.06\%) with Shulman et al $(0.12 \%)$ (3) Thermal burn $(0.03 \%)$ with Shulman et al $(0.12 \%)$ (3), Epulis fissuratum $(0.03 \%)$ with Shulman et al $(0.14 \%)$ (3) Irritational fibroma $(0.56 \%)$ with Shulman et al ( $0.19 \%)$ (3), Mathew et al (0.84\%) (2) and Corbet et al (1.0\%) (7).

\section{Tobacco induced lesions}

Among all the tobacco related lesions smoker's melanosis was common and it constituted of about $3.5 \%$. Most of them were seen on the buccal mucosa and they were in the form of ill-defined or diffused grayish-black patches.

The prevalence of leukoplakia in our study was $2.04 \%$, which was comparable with Mathew et al $(1.59 \%)$ (2) Reichert et al $(1.1 \%)(8)$ and Banoczy et al (1.3\%) (9). The most common type was homogenous leukoplakia.
Smoker's palate was seen in $1.18 \%$ of the cases, which varied when compared with shulman $(0.50 \%)$ (3) and Mathew et al $(2.77 \%)(2)$.

The presence of oral sub mucous fibrosis (OSMF) was noted in $0.7 \%$ of the population, which was far below than Mathew et al (2.01\%) (2). In the present study, stage IV OSMF (clinical evidence of fibrotic bands) was found to be very common.

In the present study, evidence of oral malignancy was seen in $0.16 \%$ of the cases, as Similar to Ikeda et al $(0.1 \%)(10)$ and Axel $(<0.1 \%)(11)$. All the lesions were confirmed by biopsy and all the reports were suggestive of squamous cell carcinoma.

Betel chewer's mucosa was recorded in $0.13 \%$ of our samples, which was consistent with Mathew et al (0.84\%) (2). Characteristically, chewer's mucosa was common in young adults.

The other tobacco related lesions recorded in our study were smoker's keratosis $0.49 \%$ and tobacco pouch keratosis $0.16 \%$.

\section{Infections}

Lesions of infectious origin in the present study were about $5.23 \%$. The most common lesion was angular cheilitis and the least common was median rhomboid glossitis. This prevalence data virtually correlated well with the following studies: Angular cheilitis $(0.30 \%)$ with Shulman et al $(0.71 \%)$, Denture stomatitis $(0.23 \%)$ with Mathew et al $(0.84 \%)$ (2), Median rhomboid glossitis $(0.03 \%)$ with Shulman et al $(0.17 \%)$ (3) and Herpes labialis- $6(0.2 \%)$ with Mathew et al $(0.6 \%)$ (2), Chiang mai $(0.9 \%)(12)$.

\section{Miscellaneous conditions}

The prevalence of Lichen planus in our study was $0.46 \%$ which was in par with Martinez et al $(0.50 \%)$ (1). The most prevalent age group was 46-60 yrs (35.7\%) and all the lesions were found in the buccal mucosa. 
In our study group, Apthous ulcer was seen in $0.56 \%$ of the cases which was comparable with Shulman et al $(0.89 \%)$ (3). The most commonest site was buccal mucosa $(70.5 \%)$ and $58.8 \%$ of them where young adults.

The presence of Lichenoid reaction was noted in $0.79 \%$ of the cases. Among them $95 \%$ of the cases were seen in the buccal mucosa and $62.5 \%$ of them were seen in the age group of $16-30 \mathrm{yrs}$.

Mucocele was observed in $0.06 \%$ of the cases and were comparable with Shulman et al $(0.02 \%)(3)$, Axel (0.10) (11), Mathew et al $(0.16 \%)(2)$. Similarly, hemangioma was seen in $0.06 \%$ of the cases, which was comparable with Shulman et al $(0.28 \%)$ (3), but very less when compared with Martinez et al $(3.2 \%)(1)$.

Other conditions recorded in the study were: Anaemic stomatitis $0.42 \%$, Allergic stomatitis $0.06 \%$ and Nevus $0.06 \%$.

\section{CONCLUSION}

From the present study, the following features were evident

- The overall mucosal changes noted in the study were $49.06 \%$, suggesting 1 in 2 patients visting dentist can present with mucosal changes.

- The most prevalent conditions in the study were developmental lesions / normal variants and linea alba was the predominant condition. The age group frequently affected was 16-30 yrs. Male predominance and predilection for buccal mucosa was noticed.

- Inspite of limited availability of tobacco products disappointingly tobacco induced lesions were seen in $17 \%$ of our cases (254 lesions out of 1489) necessitating more patient education.

On the contrary, it should be considered that the data presented here reflects only the specific patient population reported to our institution and not the community as a whole. Hence, the study can be only used as a guide for additional multicenter studies in India.

\section{REFERENCES}

1. Martinez AI, Garcia-Pola MJ. Epidemiological study of oral mucosal pathology in patients of the Oviedo School of Stomatology. Medicina Oral 2002;7:416.

2. Mathew AA, Pai KM, Sholapurkar AA, et al. The prevalence of oral mucosal lesions in patients visiting a dental school southern india. Indian J Dent Res 2008; 19(2): 99-103.

3. Shulman JD, Beach MM, Rivera-hidalgo F. The prevalence of oral mucosal lesions in US adults: Data from the third national health and Nutrition Examination Survey, 1988-1994. J Am Dent Assoc 2004;135;
1279-1286.

4. Bouquot JE. Common oral lesion found during a mass screening examination. $J$ Am Dent Assoc 1986;112:50-57.

5. Salonen L, Axell T, Hellden L. Occurrence of oral mucosal lesions, the influence of tobacco habits and an estimate of treatment time in adult Swedish population. J Oral Pathol Med 1990;19: 170-176.

6. Bouquot JE, Gorlin RJ. Leukoplakia, lichen planus, and other oral keratosis in 23,616 white Americans over the age of 35 years. Oral Surg Oral Med Oral Pathol 1986;61:373-381.

7. Corbet EF, Holmgren CJ, Philipsen HP. Oral mucosal lesions in 65-74 year old hongkong Chinese. Community Dent Oral Epidemiol 1994;22:392-395.

8. Reichart PA, Mohr U, Srisuwan S, Geerlings $\mathrm{H}$, et al. Precancerous and other oral mucosal lesions related to chewing, smoking and drinking habits in Thailand. Community Dent Oral Epidemiol 1987;15:152-160.

9. Banoczy J, Rigo O. Prevalence study of oral precancerous lesions with a complex screening system in hungary. Community Dent Oral Epidemiol 1991;19:265-267.

10. Ikeda N, Handa Y, Khim SP, et al. Prevalence study of oral mucosal lesions in a selected Cambodian population. Community Dent Oral Epidemiol 1995;23:49-54.

11. Axel T. A prevalence study of oral mucosal lesion in an adult Swedish population. Thesis Odontol revy 1976;27:100-103.

12. Axel T et al. Prevalence of oral soft tissue lesions in out patients at two Malaysians and Thai Dental school. Community Dent Oral Epidemiol 1990;18:95-99. 